\title{
Tertiary Treatment Process of Preserved Wastewater
}

\author{
Qingyu Wang ${ }^{1, \mathrm{a}}$, Yongli Zhang ${ }^{1, \mathrm{~b}}$, Kai Lin $^{1, \mathrm{c}}$ and Xiaolang Chen ${ }^{1, \mathrm{~d}}$ \\ ${ }^{1}$ School of Chemical and Environmental Engineering, Hanshan Normal University, Chaozhou 521041, \\ China \\ awqy_71813@163.com, ${ }^{\mathrm{b}} \mathrm{zyl} \_12382 @ 163 . c o m,{ }^{\mathrm{C}} \mathrm{Kai} 306301 @ 163 . c o m,{ }^{\mathrm{d}} 863394794 @$ @q.com
}

\begin{abstract}
The effects of the composite coagulants on coagulation sedimentation for the preserved wastewater was investigated by changing the composite coagulant dosages, and the coagulant was composed of polymeric ferric sulfate (PFS), polyaluminium chloride (PAC), and polyaluminum ferric silicate (PAFSC), while the effect of the tertiary treatment process on the preserved wastewater was tested, which was exceeded the standard seriously. The results showed that $400 \mathrm{mg} / \mathrm{L}$ was the optimum composite coagulant dosage. The removal rates of salt and sugar were as high as $99.1 \%$ and $99.5 \%$ respectively, and the removal rates of $\mathrm{COD}_{\mathrm{Cr}}$ and SS were $99.3 \%$ and $96.0 \%$, respectively after the preserved wastewater was treated by the tertiary treatment technology, which both reached the primary standard of "The Integrated Wastewater Discharge Standard" (GB8978-1996).
\end{abstract}

Keywords: tertiary treatment process; preserved wastewater; composite coagulant; salt removal rate; sugar removal rate; $\mathrm{COD}_{\mathrm{Cr}}$ removal rate; $\mathrm{SS}$ removal rate

\section{Introduction}

Preserved fruits, is a popular fruit and vegetable pickled food with local characteristics in China, using various fresh fruits as raw materials, after a series of processes such as pickling, rinsing, sugar boiling, dipping, then natural spices, edible pigments, preservatives, and other food additives are added, finally, the dry state or semi dry state products are obtained by solarization or artificial drying [1,2]. Preserved fruits are mainly divided into three categories: Beijing type candied fruit cake, Suzhou style preserved fruits cake, and Cantonese style preserved fruits. And the Chaoshan preserved fruits are the most famous sweetmeat in Cantonese style preserved fruits, which occupies great share of the preserved fruits of the market due to the rich fruit resources, unique local flavor, and centuries-old local folk traditional craft in Chaoshan area [3].

Although part of the problems about "high yield but low income" for the Chaoshan fruit planting industry are solved by the production of preserved fruits, which can increase the income of the farmers, the pollution generated in the productive process of preserved fruits 
also can not be ignored. The salt and sugar concentrations of preserved wastewater are high because improving the salt and sugar concentrations in the productive process of preserved fruits is beneficial to prevent bacterial growth and extend the shelf life of food [4]. Meanwhile, the concentrations of $\mathrm{COD}_{\mathrm{Cr}}$ and SS of preserved wastewater also are high, river water and nearby farmlands are easily polluted when preserved wastewater discharges without treatment [5]. Therefore, it is urgent to seek a technology which can dispose preserved wastewater properly. The research of treatment technology for preserved wastewater has an important significance in saving energy, making full use of water resources, and reducing emissions, showing a significant social benefit. Meanwhile, it can reduce the $\mathrm{COD}_{\mathrm{Cr}}$ concentration substantially, exhibiting an obvious economic effectiveness. Nevertheless, there are seldom reports about preserved wastewater treatment at present.

The influence of the composite coagulant dosage on the effect of coagulation sedimentation for the preserved wastewater was investigated, and the tertiary treatment technology was adopted to dispose preserved wastewater, using salt removal rate, sugar removal rate, $\mathrm{COD}_{\mathrm{Cr}}$ removal rate, and $\mathrm{SS}$ removal rate as evaluation criterions to investigate the treatment effect of the tertiary treatment technology for the preserved wastewater.

\section{Materials and Methods}

\subsection{Experimental Wastewater}

The experimental wastewater came from a preserved fruits factory in Chaozhou, the concentration mass percentage of salt in the wastewater was as high as $35 \%$, and the concentration of the sugar was up to $15 \%$, while the concentration of $\mathrm{COD}_{\mathrm{Cr}}$ was up to 7000 mg/L, which exceeded "The Integrated Wastewater Discharge Standard" (GB8978-1996) 70 times, and the concentration of SS was up to $1500 \mathrm{mg} / \mathrm{L}$, exceeding "The Integrated Wastewater Discharge Standard" (GB8978-1996) about 22 times.

\subsection{Water Quality Analysis Method and Testing Equipment}

Table 1 water quality analysis method and testing equipment

\begin{tabular}{|c|c|c|}
\hline Analysis Item & Test method & Equipment and model \\
\hline Salt concentration & $\begin{array}{l}\text { Direct reading } \\
\text { instrument }\end{array}$ & Salt analyzer SAT5000 \\
\hline Sugar concentration & $\begin{array}{l}\text { Direct reading } \\
\text { instrument }\end{array}$ & Sugar analyzer SA4050 \\
\hline $\mathrm{COD}_{\mathrm{Cr}}$ & Dichromate titration & $\begin{array}{c}\mathrm{COD}_{\mathrm{Cr}} \text { national standard } \\
\text { device }\end{array}$ \\
\hline SS & Gravimetric analysis & Electronic balance FA2004N \\
\hline
\end{tabular}

The $\mathrm{COD}_{\mathrm{Cr}}$ removal rate was calculated based on the equation (1):

$$
C O D_{\mathrm{Cr}}=\frac{\left(V_{0}-V_{1} \times \mathrm{c} \times 8 \times 1000\right)}{V}
$$

where $\mathrm{V}_{0}$ was the dosage of ammonium ferrous sulfate standard solution when titrate blank (mL), while $\mathrm{V}_{1}$ was the dosage of ammonium ferrous sulfate standard solution when titrate water sample $(\mathrm{mL}), \mathrm{V}$ was the volume of water sample $(\mathrm{mL}), \mathrm{C}$ was the concentration of standard solution of ammonium ferrous sulfate ( $\mathrm{mol} / \mathrm{L})$.

The removal rate of SS was calculated as the equation (2) and (3): 


$$
\begin{aligned}
& S=\frac{\left(X-X_{0}\right) \times 10^{6}}{V} \\
& \eta=\frac{S_{0}-S}{S} \times 100 \%
\end{aligned}
$$

where $\mathrm{S}_{0}$ was the concentration of initial suspended solids, $\mathrm{S}$ was the concentration of effluent suspended solids, $\mathrm{X}$ was the quality of cylinder and suspension, $\mathrm{X}_{0}$ was the quality of measuring cylinder.

\section{Experimental}

Ten measuring cylinders with $100 \mathrm{ml}$ preserved wastewater were taken, and the influences of different composite coagulant dosages on the effect of coagulation sedimentation for the preserved wastewater were compared by changing the composite coagulant dosage which was composed of PFS, PAC, and PAFSC (ratio of 1:1:1) in the measuring cylinders in order to determine the optimum dosage of the composite coagulant, and then used in the tertiary treatment technology to dispose the preserved wastewater, investigating the effect of the tertiary treatment technology on the preserved wastewater.

\section{Results and Discussion}

\subsection{Influence of Composite Coagulant Dosage on the Effect of Coagulation Sedimentation}

The influence of the composite coagulant dosage on the effect of coagulation sedimentation for the preserved wastewater was shown in Fig.1, and the composite coagulant dosages were $0,50,100,150,200,250,300,350,400$, and $450 \mathrm{mg} / \mathrm{L}$, respectively. As shown in Fig.1, coupled with the increase of the composite coagulant dosage, the wastewater was becoming clearer and the precipitation increased gradually. With a comprehensive consideration of the result and cost, $400 \mathrm{mg} / \mathrm{L}$ was chosen as the most suitable composite coagulant dosage.

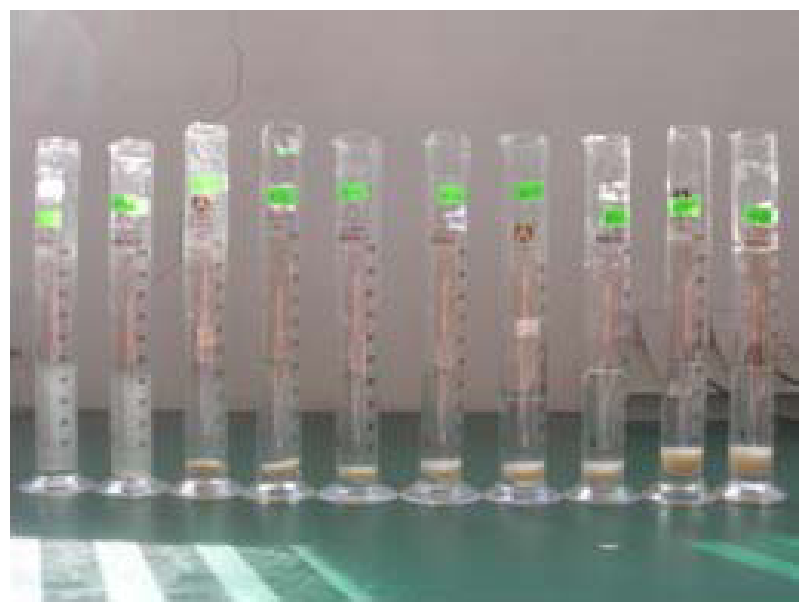

Fig.1 Influence of composite coagulant dosage on the effect of coagulation sedimentation 


\subsection{Tertiary Treatment Technology}

\subsubsection{Primary Treatment}

The preserved wastewater was transported to the $\mathrm{pH}$ regulation pool after the pretreatment which carried out in a filtering basin equipped with quartz sands and waste ceramic filter materials, and alkali liquor was added into the $\mathrm{pH}$ regulation pool with constant stirring in order to regulate the $\mathrm{pH}$ to 10 . When the intermixture was transported to the coagulation pool, $400 \mathrm{mg} / \mathrm{L}$ composite coagulants were added into the coagulation pool and stirred at $50 \mathrm{r} / \mathrm{min}$ for $10 \mathrm{~min}$. Subsequently, transported to the flocculation pool, and 10 $\mathrm{mg} / \mathrm{L}$ polyacrylamide flocculants were added into the flocculation pool, stirring at $30 \mathrm{r} / \mathrm{min}$ for $5 \mathrm{~min}$. The wastewater overflowed to the primary settling tank after stirring, and the wastewater which came from the top of the primary settling tank overflowed to the sink while the sludge was settled to the bottom of the primary settling tank through an inclined tube.

\subsubsection{Secondary Treatments}

The wastewater in the collecting basin was injected into the biochemical reaction tank by a pump, and flowed through the filling area from the bottom to top, and the lower part of the filling area was the pebble layer, and the upper part of the filling area was a ceramic layer, while the filtering speed of the wastewater was $2 \mathrm{~m} / \mathrm{h}$; Under the function of ceramic layer, wastewater was discharged from the top of the biochemical reaction tank.

\subsubsection{Tertiary Treatment}

The wastewater discharged from biochemical reaction pool was transported to Fenton oxidation pool, which was added with $10 \mathrm{~g} / \mathrm{L}$ iron vitriol, stirred at $30 \mathrm{r} / \mathrm{min}$ for $10 \mathrm{~min}$ and then quickly added in $30 \mathrm{~mL} / \mathrm{L}$ hydrogen peroxide solution at the mass fraction of $30 \%$, stirred at $30 \mathrm{r} / \mathrm{min}$ for $12 \mathrm{~min}$ after mixing. Afterwards the wastewater was transferred to the neutralization pool, and alkali liquor was added into the pool, regulating the $\mathrm{pH}$ to 7.5 , after which the mixture was let stand for $3 \mathrm{~h}$ until precipitating. Then the wastewater overflowed from the upper of the pool, which was subsequently transported into the MBR membrane pool equipped with filter on the top, so the sludge and the wastewater were separated respectively after entering into the filter. The sludge was then dried in the drying processor and recycled after disinfection treatment, while the wastewater flowed into the MBR membrane pool treated by filtration process again. Subsequently, the wastewater which filtered by MBR was introduced into the reverse osmosis RO membrane pool to be filtered again. The intercept rate of standard $\mathrm{RO}$ membrane for $\mathrm{NaCl}$ was more than $99 \%$, moreover, the interception for multivalent ions and organic matter was more thoroughly, thus it has an excellent treatment effect for the preserved wastewater. Eventually, the wastewater was disinfected by the method of UV after multiprocessing. The ultraviolet disinfection device broke the structure of various viruses, bacteria and other pathogens in the water by producing ultraviolet photon energy, which was employed in tertiary wastewater treatment plants extensively.

\subsubsection{Process Flow Diagram of Preserved Wastewater}

The process flow diagram of preserved wastewater was shown in Fig.2. The preserved wastewater was reused in industrial production, factory district greening and interior miscellaneous use after pretreatment, tertiary treatment and post-treatment. And the recycled sludge was disposed in landfills. 


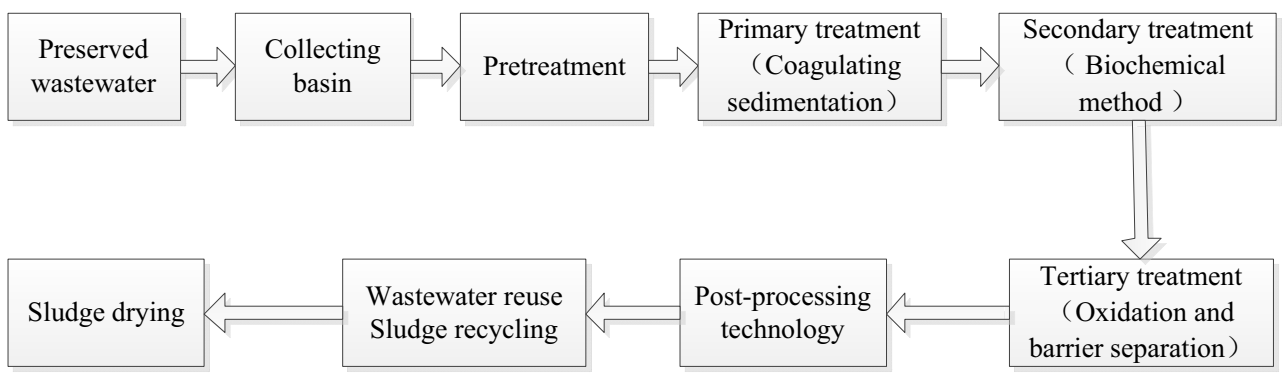

Fig.2 Process flow diagram of preserved wastewater

\subsubsection{Results of Tertiary Treatment for Preserved Wastewater}

As shown in Fig.3 and Fig.4, the removal rates of salt and sugar were as high as $99.1 \%$ and $99.5 \%$ respectively, and the removal rates of $\mathrm{COD}_{\mathrm{Cr}}$ and $\mathrm{SS}$ were $99.3 \%$ and $96.0 \%$, respectively after the preserved wastewater was treated by the tertiary treatment technology. Since the concentrations of salt and sugar in treated effluent were low, so it has lost inhibitory effect on the growth of microorganisms in water, meanwhile $\mathrm{COD}_{\mathrm{Cr}}$ and SS reached the primary standard of "The Integrated Wastewater Discharge Standard" (GB8978-1996).

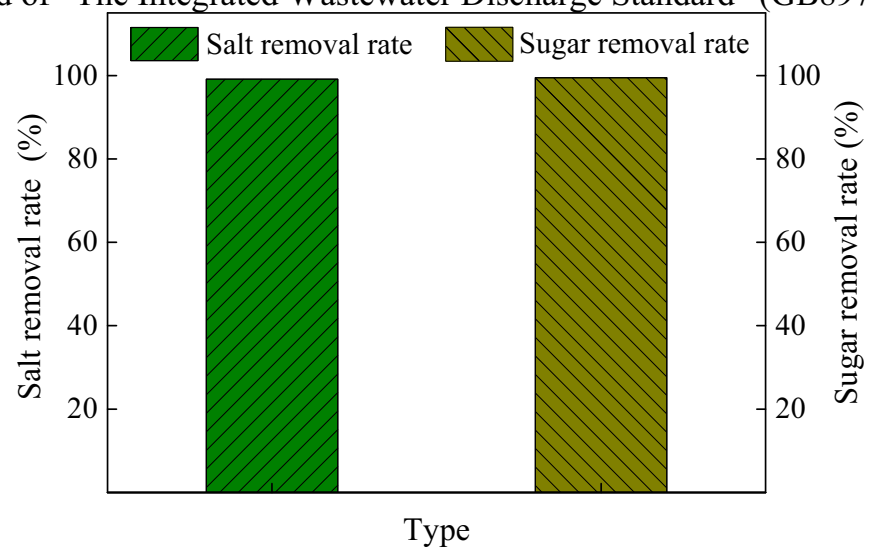

Fig.3 Salt and sugar removal rates of the wastewater after tertiary treatment



Fig.4 $\mathrm{COD}_{\mathrm{Cr}}$ and SS removal rates of the wastewater after tertiary treatment 


\section{Conclusions}

(1) By investigating the influence of composite coagulant dosage which was composed of polymeric ferric sulfate (PFS), polyaluminium chloride (PAC), and polyaluminum ferric silicate (PAFSC) on treatment effect, $400 \mathrm{mg} / \mathrm{L}$ was confirmed as the optimum composite coagulant dosage.

(2) The preserved wastewater was reused in industrial production, factory district greening and interior miscellaneous use after the primary treatment of coagulation sedimentation, secondary treatment of biochemical method, tertiary treatment of oxidation and barrier separation and post-treatment of ultraviolet disinfection. And the recycled sludge was disposed in landfills.

(3) The removal rates of salt and sugar were as high as $99.1 \%$ and $99.5 \%$ respectively, and the removal rates of $\mathrm{COD}_{\mathrm{Cr}}$ and $\mathrm{SS}$ were $99.3 \%$ and $96.0 \%$, respectively after the preserved wastewater was treated by the tertiary treatment technology, and $\mathrm{COD}_{\mathrm{Cr}}$ and $\mathrm{SS}$ of the treated effluent reached the primary standard of "The Integrated Wastewater Discharge Standard" (GB8978-1996).

\section{Acknowledgments}

This work has been supported by the 2015 Guangdong science and technology project (2015A020208019).

\section{References}

1. Y S Yu, Y S Zhang, G S Xiao, et al. Investigation on the Microbial Species in the Preserved Fruits, Guangdong Agr Sci. 2 (2008) 68-70.

2. $\mathrm{X} F$ Zeng, $\mathrm{S} \mathrm{H}$ Ye, W D Bai. Advances on $\mathrm{SO}_{2}$ Removal Technology from Cantonese-Style Preserved Fruit, Food Mach. 27 (2011) 156-159.

3. Y Chen, Q H Yang. Discussing the Oligosacharide's Application in the Preserved Fruits, Food Sci. 25 (2004) 215-217.

4. B Zhang, H M Chen, Q Wang, et al. Study on Improvement of Technology Condition of Hunan Tradition Preserved Ham, Sci Technol Food Ind. 29 (2008) 140-142.

5. W Y Li, Z P Peng, J H Yu, et al. Wastewater Pollution Characteristics from Typical Intensive Pig Farms in the Pearl River Delta and Its Ecological Risk Assessment, Environ Sci. 34 (2013) 3963-3968. 